\title{
NONLINEAR CONTROLLER DESIGN FOR A SHELL AND TUBE HEAT EXCHANGER - AN EXPERIMENTATION APPROACH
}

\author{
${ }^{1}$ MITHUN.P, ${ }^{2}$ SATHEESHBABU.R, ${ }^{3}$ I.THIRUNAVUKKARASU, ${ }^{4}$ V.I.GEORGE, ${ }^{5}$ SHREESHA.C \\ ${ }^{1}$ PG Student, M.Tech (Control Systems), ${ }^{2}$ Research Scholar, ${ }^{3}$ Associate Professor, ${ }^{4,5}$ Professors, \\ Department of Instrumentation and Control Engineering, MIT, Manipal University, India. \\ E-mail: ${ }^{3}$ it.arasu@manipal.edu
}

\begin{abstract}
In this paper the outlet water temperature control of the shell and tube heat exchanger was implemented in real time system with the Generic Model Control (GMC) and adaptive control technique in simulation. The steady state model of the heat exchanger is used for the GMC and the dynamic model of the shell and tube heat exchanger is used for the adaptive control technique. MATLAB-2010-Simulink was used as a tool to implement the control algorithm in hardware loop.
\end{abstract}

\section{INTRODUCTION}

Heat exchangers are devices that facilitate the exchange of heat between two fluids that are different temperature while keeping them from mixing with each other. Heat exchangers are mainly used in chemical processing and power production plants. Since they are relatively easy to use experimentally and they show nonlinear and non-stationary properties, the heat exchangers are frequently used as a demonstration of control. This paper deals with two types of controllers. Generic model controller (GMC) based on the steady state model of the STHE [6] and Adaptive controller [1,2] based on the dynamic model of STHE.

The generic model control uses the inverse of the steady state model of the STHE to control the nonlinear process. The model may contain empirical features or may be purely empirical. GMC integrates the process model with proportional and integral error terms similar to PI controller to adjust the control input to achieve a desired closed loop trajectory.

In adaptive control, the controller is divided into two parts. Non-linear static part (NSP) and linear dynamic part(LDP). The non-linear part of the controller is developed using simulated or measured steady state characteristics of the STHE, its inversion, exponential approximationand subsequently its differentiation. Then NSP and non-linear model of STHE is approximated by a continuous time external model (CT-ELM).The parameter of the CT-ELM is obtained by the application of an external delta model with same structure as the CT-ELM model. Then in dynamic linear part of the controller, an adaptive controller is developed using polynomial approach and pole placement method.

\section{PHYSICAL SYSTEM: SHELL AND TUBE HEAT EXCHANGER}

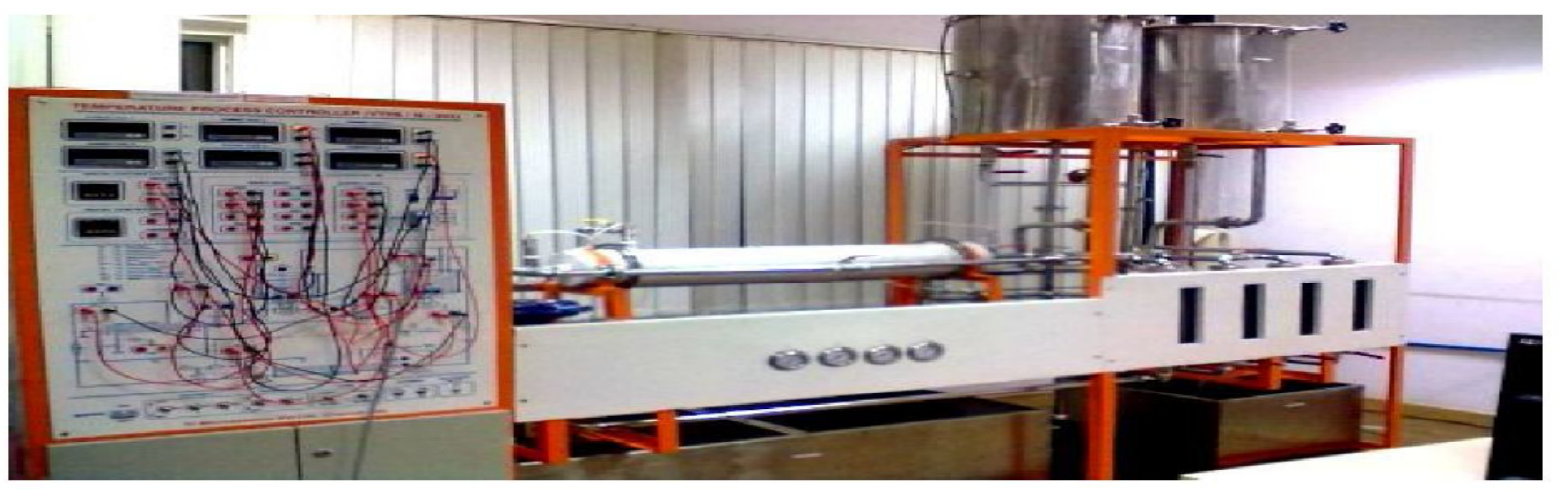

Fig.1. Heat Exchanger Physical Experimentation Experimental Setup

Table.1.Technical Specifications of the Heat Exchanger Setup

\begin{tabular}{|l|l|}
\hline Type & Shell and Tube \\
\hline Shell material & SS 316 \\
\hline Tube material & Copper \\
\hline Tube length & $750 \mathrm{~mm}$ \\
\hline Shell diameter & $150 \mathrm{~mm}$ \\
\hline Number of tubes & 37 \\
\hline Tubes diameter & $6 \mathrm{~mm}$ \\
\hline
\end{tabular}

The shell and tube heat exchanger has hot water in the tube side and cold water in the shell side. The outlet temperature of the hot water is controlled by varying the cold water flow rate. So that outlet hot water temperature is the controlled variable and inlet cold water temperature is the manipulated variable.

\section{CONTROL METHODOLOGY}


As discussed in the abstract in this paper two control algorithms were designed, simulated and implemented for a shell and tube heat exchanger process namely i) Generic Model Control ii) Adaptive Control.

\subsection{Generic Model Control (GMC)}

The steady state model for GMC is developed based on the energy balance equation of the shell and tube heat exchanger described as follows.

The heat transfer rate is

$Q_{H X \text { Trans }}=U A\left(\frac{\left(T_{O}+T_{i n}\right)_{h}}{2}-\frac{\left(T_{O}+T_{i n}\right)_{c}}{2}\right)$

The heat rate gained by the cold water is

$Q_{\text {Watergained }}=F \rho C_{P}\left(T_{O-} T_{\text {in }}\right)_{c}$

WhereU: overallheattransfer coefficient, A: surfacearea T0: water outlet temperature, Tin: waterinlettemperature, $\mathrm{F}$ : cold waterinlet flow rate, $\rho$ : densityofwater, $\mathrm{Cp}$ : waterheatcapacity,subscripts denoted $\mathrm{h}$ for hot water and $\mathrm{c}$ denoted for cold water. The steady-state equation for hot water outlet temperature can be derived by combining Eqs (1)\&(2).

$$
T_{0 h}=\left(\frac{2 F \rho C_{P}\left(T_{O}-T_{i n}\right)_{c}}{U A}\right)+\left(T_{O}+T_{i n}\right)_{c}-T_{i n h}
$$

The cold water inlet valve has equal percentage characteristics. There for the flow rate and control signal can be related as

$$
F=m_{0} e^{\beta u}
$$

Where $\mathrm{u}$ is the control signal. $m_{0}$ and $\beta$ are constants and empirically determined from the installed valve characteristic.

In GMC-SS, the steady-state model is inverted to get the control action

By substituting equation(4) in (3) and rearranging, the control action, i.e., valve percentage is given by

$$
u=\frac{1}{\beta} \ln \left[\left(\frac{U A}{2 m m_{0} \rho C_{P}}\left(\frac{\left(T_{O}+T_{i n}\right)_{h}-\left(T_{O}+T_{i n}\right)_{C}}{\left(T_{O} T_{i n}\right)_{c}}\right)\right)\right]
$$

Block Diagram Of The Gmcis Shown In Fig.2.

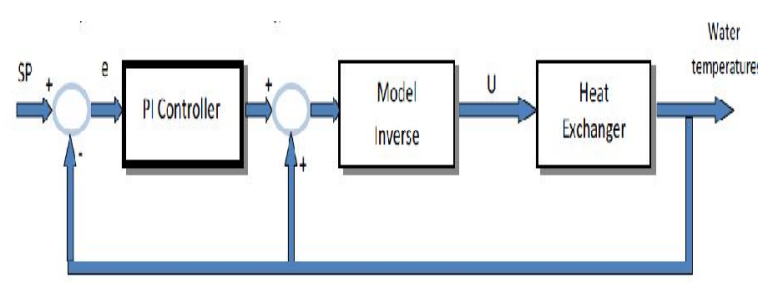

Fig .2 GMC Controller block diagram

The concept of GMC control action is to aimfora $y$ value

(CV)targetabout $10 \%$ or $20 \%$ beyondthesetpoint. The logic is that a target value slightly beyond makes the controller push the process a bit fast erininitial stages. Then, inlater stages as the process approaches these tpoint,the target relaxes to the set point. The out puttargetis

$$
y_{\text {target }} y_{\text {meas }}+K_{1}\left(y_{s p}-y_{\text {meas }}\right)=y_{\text {meas }}+K_{1}(e)
$$

The model is not exactly true to the process. There for the manipulated variable calculated for inverse model will not make the process be exactly at the set point. So, the output will contain an offset error. In GMC, this offset is eliminated by integrating the actuating error. The output target can be set by a PI output added to the measurement:

$$
y_{\text {target }=} y_{\text {meas }}+K_{1}(e)+K_{2} \int e d t
$$

Where $K_{1}$ is the proportional gain, varies between

1.1 and1.2. And $K_{2}$ is integral gain $\frac{K_{1}}{\tau_{i}}$.

The target value can be written as

$$
y_{\text {tangel }=} y_{\text {meas }}+K_{1}\left(e+\frac{1}{\tau_{i}} \int e d t\right)
$$

This equation shows the PI action in the GMC. Hence the target is

$$
y_{\text {target }} y_{\text {meas }}+\text { PI_output }
$$

The target value given by Eq. (9) is substituted into the steady-state model inverse of Eq. (5) to generate the control action.

\subsection{Adaptive control}

Adaptive control uses the dynamic model of the process for developing the controller. The dynamic model of a counter flow cooling shell and tube heat exchanger can be described by three partial differential equations.

$$
\begin{aligned}
& \frac{\partial T_{r}}{\partial t}+v_{r} \frac{\partial T_{r}}{\partial z}=c_{1}\left(T_{w}-T_{r}\right) \\
& \frac{\partial T_{w}}{\partial t}-c_{2}\left(T_{r}-T_{w}\right)+c_{1}\left(T_{c}-T_{w}\right) \\
& \frac{\partial T_{c}}{\partial t}-v_{r} \frac{\partial T_{c}}{\partial z}=c_{4}\left(T_{w}-T_{c}\right)
\end{aligned}
$$

The parameters in equations (10)-(12) are

$$
\begin{gathered}
v_{r}=\frac{4 q_{r}}{n_{1} \pi d_{1}^{2}}, v_{c}=\frac{4 q_{c}}{\pi\left(d_{3}^{2}-n_{1} d_{1}^{2}\right)}, c_{1}=\frac{4 \alpha_{1}}{d_{1} \rho_{r} c_{p r}}, c_{2}=\frac{4 d_{1} \alpha_{1}}{\left(d_{2}^{2}-d_{1}^{2}\right) \rho_{w} c_{p w}} \\
c_{3}=\frac{4 d_{2} \alpha_{2}}{\left(d_{2}^{2}-d_{1}^{2}\right) \rho_{w} c_{p w}}, c_{4}=\frac{4 n_{1} d_{2} \alpha_{2}}{\left(d_{3}^{2}-n_{1} d_{1}^{2}\right) \rho_{c} c_{p c}}
\end{gathered}
$$

Where $t$ stands for the time, $z$ for the axialspace variable, $T$ for temperatures, $q$ for flow of fluids, $v$ for fluid flow velocities, $d_{1}$ for inner diameter of the tube, $d_{2}$ for outer diameter of the tube, $d_{3}$ for diameter of theshell, $\rho$ for densities, $c_{p}$ for specific heat capacities, $\alpha$ for heat transfer coefficients, $n_{1}$ is the number of tubesand $L$ is the length of tubes. Subscripts denoted $r$ describe the hot water, $w$ the metal walls oftubes, $c$ cold water and the superscript ssteady-state values. As from ref. [3] the parameters and steady sate inputs used are given in Table 2. 
Table 2.Parameters and Steady-State Inputs

\begin{tabular}{|l|l|}
\hline$L=8 \mathrm{~m}$ & $n 1=1100$ \\
\hline$d 1=0.022 \mathrm{~m}$ & $\begin{array}{l}d 2=0.024 \mathrm{~m} \\
\rho_{r}=985 \mathrm{~kg} / m^{3}\end{array}$ \\
\hline$\rho_{w}=7800 \mathrm{~kg} / \mathrm{m}^{3}$ & $\rho_{c}=998 \mathrm{~kg} / \mathrm{m}^{3}$ \\
\hline$c_{p r}=4.05 \mathrm{~kJ} / \mathrm{kg} \mathrm{K}$ & $c_{p w}=0.71 \mathrm{~kJ} / \mathrm{kg} \mathrm{K}$ \\
\hline$c_{p c}=4.18 \mathrm{~kJ} / \mathrm{kg} \mathrm{K}$ & $\alpha_{1}=5.8 \mathrm{~kJ} / \mathrm{K}$ \\
\hline$\alpha_{2}=3.6 \mathrm{~kJ} / \mathrm{m}^{2} \mathrm{~s} \mathrm{~K}$ & $T_{r 0}^{s}=373 \mathrm{~K}$ \\
\hline$T_{c 0}^{s}=293 \mathrm{~K}$ & $q_{c}^{s}=.09 \mathrm{~m}^{3} / \mathrm{s}$ \\
\hline$a_{r}^{s}=.03 \mathrm{~m}^{3} / \mathrm{s}$ & \\
\hline
\end{tabular}

Finite difference method is employed for the computation of steady state and dynamic characteristics. For this the space interval $z \in<0, L>$ is divided into a set of discrete node points $\left\{z_{i}\right\}$ for $\mathrm{i}=1$ to $\mathrm{n}$.

Using finite difference method PDEs are approximated by a set of ODEs in the form

$$
\begin{aligned}
& \frac{d T_{r}(i)}{d t}=-\left(\frac{v_{r}}{h}+c_{1}\right) T_{r}(i)+\frac{v_{r}}{h} T_{r}(i-1)+c_{1} T_{w}(i) \\
& \frac{d T_{w}(i)}{d t}=c_{2}\left[T_{r}(i)-T_{w}(i)\right]+c_{3}\left[T_{c}(i)-T_{w}(i)\right] \\
& \frac{d T_{c}(i)}{d t}--\left(\frac{v_{c}}{h}+c_{4}\right) T_{s}(j)+\frac{v_{c}}{h} T_{r}(j+1)+c_{4} T_{w}(j)
\end{aligned}
$$

Fori $=1 \ldots, n, j=n-i+1$, and, with initial conditions $T_{r}(i, 0)=T_{r}^{s}(i), T_{w}(i, 0)=T_{w}^{s}(i)$, $T_{c}(i, 0)=T_{c}^{s}(i) . \mathrm{h}=\mathrm{L} / \mathrm{n}$ is the discretization step.

The Steady State Characteristics Of The Heat Exchanger Are Shown In Fig.3.

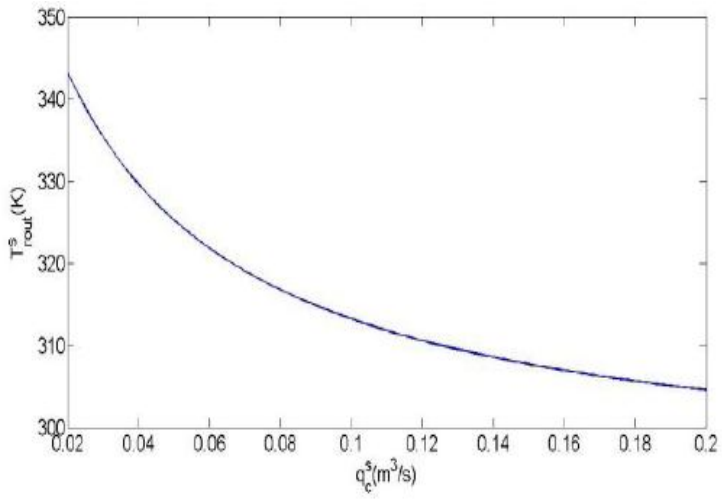

Fig. 3 steady state characteristics of the heat exchanger

From this the operating point around which the changes take place during the controlis chosen as $q_{c}^{s}$ $=.09$ and $T_{\text {rout }}^{s}=314.82$. The upper and lower limit of the operating points is $q_{c}^{U}=.18 \mathrm{~m}^{3} / \mathrm{s}, q_{c}^{L}=.05$ $m^{3} / s$

$T_{\text {rout }}^{L}=332.09 \mathrm{~K}, T_{\text {rout }}^{L}={ }_{301.21}$. The control input and controlled output are considered in the form $u(t)=\Delta q_{0}(t)=q_{c}(t)-q_{c}^{s}$ and $y(t)=T_{\text {rout }}(t)-T_{\text {rout }}^{s}$

\section{CONTROLLER DESIGN}

As previously introduced, the controller consists of a nonlinear static part and a linear dynamic part as shown in Fig.4.

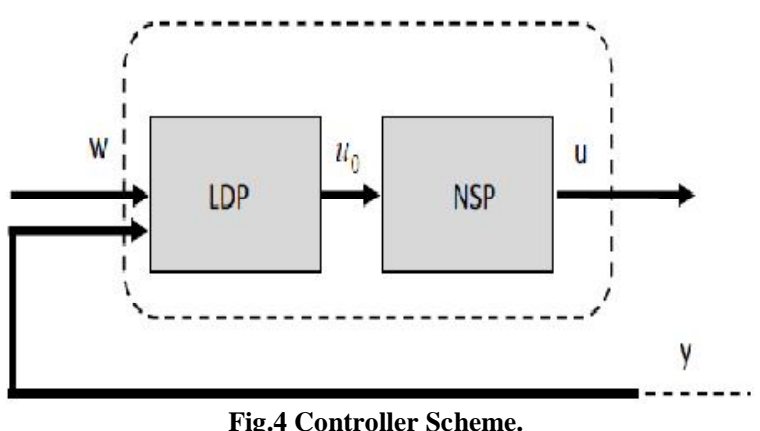

The LDP creates a linear dynamic relation which represents a difference of the hot water outlet temperature adequate to its desired value. Then, the NSP generates astatic nonlinear relation between $u_{0}$ and a correspondingincrement (decrement) of the coolant flow rate.

\subsection{Non Linear Static Part of the Controller}

The normalized values of flow rate and temperature are obtained by

$$
\zeta=\frac{q_{c}^{s}-q_{c}^{L}}{q_{r}^{U}-q_{r}^{L}}, \psi=\frac{T_{\text {rout }}^{s}-T_{\text {rout }}^{L}}{T_{\text {rout }}^{U}-T_{\text {rout }}^{L}}
$$

In practice, the error will be present in measured data. So that the simulated steady state characteristics in reality is shown in Fig.5.

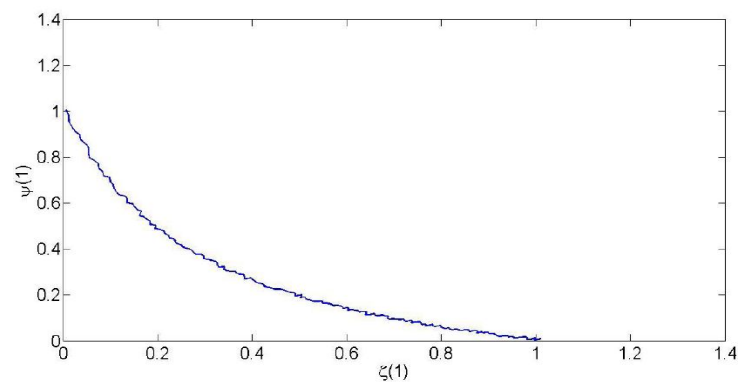

Fig 5. Steady-state characteristics in presence of disturbance

The inverse characteristic is approximated by second order exponential function as shown in Fig.6

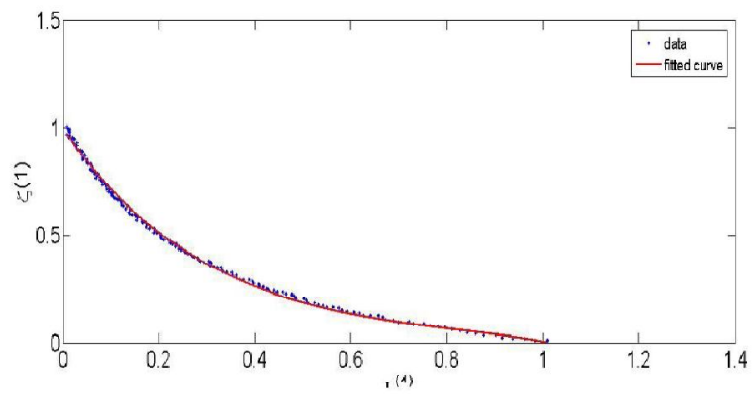

Fig 6 Approximation of the inverse characteristics 
The approximation has done using least square method and has the form

$$
\xi=-1.28+0.69 e^{-1.14}+1.7 e^{-0.26 \%}
$$

Now for each $T_{\text {rout }}$ the difference of the coolant flow rate in the output of NSP can be computed as

$$
u(t)=\Delta q_{c}(t)=\frac{q_{c}^{U}-q_{c}^{L}}{T_{\text {rout }}^{U}-T_{\text {rout }}^{L}}\left(\frac{d \zeta}{d \psi}\right)_{\psi T_{\text {rou }}} u_{0}(t)
$$

\subsection{CT and Delta External Linear Model}

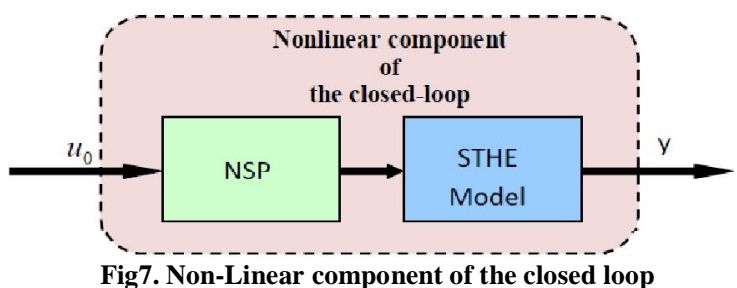

The non-linear component of the closed loop consisting of NSP and the STHE model. The step response of the non-linearcomponent simulated around above defined operating point is shown in Fig.8.

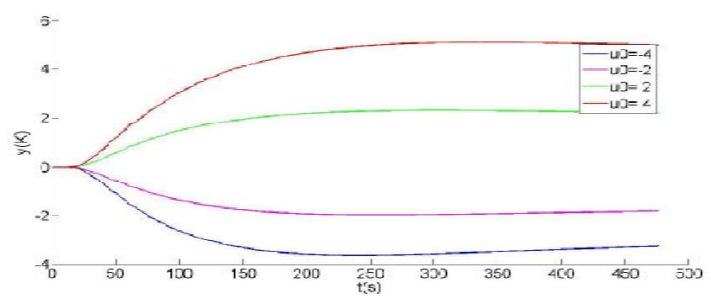

Fig 8. Step Response Of The Nonlinear Component

From the above step response the second order CTELM hasbeen chosen in the form of the second order lineardifferential equation

$y(t)+a_{1} y(l)+a_{0} y(t)=b_{0} u(t)$

Or, in the transfer function representation as

$$
G(s)=\frac{b_{0}}{s^{2}+a_{1} s+a_{0}}
$$

\subsection{Parameter estimation}

The parameters $a_{1}, a_{0}, b_{0}$ is obtained by delta model parameter identification method [5]. The delta model corresponding to the CT-ELM model has the form

$\delta^{2} y\left(t^{\prime}\right)+a_{1}^{\prime} \delta y\left(t^{\prime}\right)+a_{0}^{\prime} y\left(t^{\prime}\right)=h_{0}^{\prime} u\left(t^{\prime}\right)$

Where $\delta$ is the forward shift operator. $t$ is the discrete time. As the sampling period is too small, the delta operator becomes the derivative operator and delta model parameters $a_{1}^{\prime}, a_{0}^{\prime}, b_{0}^{\prime}$ reaches the $a_{1}, a_{0}$ ,$b_{0}$ of the CT model

\subsection{Linear Dynamic Part of the Controller}

The feedback control loop is shown in Fig.9.

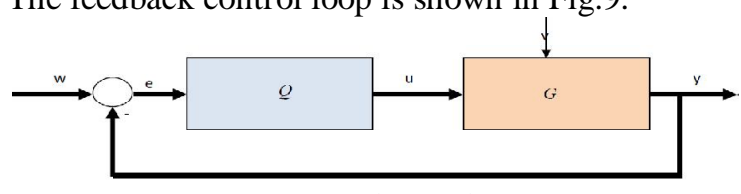

Fig 9. Control System Structure
In this $\mathrm{w}$ is the reference signal and $\mathrm{v}$ is the disturbance, $y$ is the controlled output and $u$ is the control input.The transfer function $G$ is given by (22). Both the reference $w$ and the disturbance $v$ are considered to be step functions. The controller has the transfer function in the form

$$
Q(s)=\frac{q(s)}{p(s)}
$$

Where $q$ and $p$ are polynomials in $s$ that fulfil the condition $\operatorname{deg} q \leq \operatorname{deg} p$. The controller is designed using polynomial approach.A controller which satisfies stability, internalproperness, asymptotic tracking of step referenceand step disturbance attenuation is given by a solution of the polynomial equation

$$
a(s) p(s)+b(s) q(s)=d(s)
$$

With a stable polynomial $d(s)$ on the right side. For step input signals $w$ and $v$, the polynomial $p$ is in the form

$$
p(s)=s \tilde{p}(s)
$$$$
\mathrm{y}
$$

Then, the controller transfer functions take forms

$$
Q(s)=\frac{q(s)}{s p(s)}=\frac{q_{2} s^{2}+q_{1} s+q_{0}}{s\left(s+p_{0}\right)}
$$

In this paper, the polynomial $d$ with roots determining the closed-loop poles is chosen as $d(s)=n(s)(s+\alpha)^{2}$

Where $n$ is a stable polynomial obtained by spectral factorization

$u^{*}(s) u(s)=r^{*}(s) r(s)$

$\alpha$ is a tuneable parameter that can be selected by simulation experiments.

The polynomial $\mathrm{n}$ has the form

$n(s)=s^{2}+n_{1} s+n_{0}$

With coefficients

$n_{u}-\sqrt{a_{u}^{2}}, n_{1}-\sqrt{a_{u}^{2}+2 n_{u}-2 a_{0}}$

Then, the controller parameters can be obtained fromsolution of the matrix equation

$$
\left(\begin{array}{cccc}
1 & 0 & 0 & 0 \\
a_{1} & b_{0} & 0 & 0 \\
a_{0} & 0 & b_{0} & 0 \\
0 & 0 & 0 & b_{0}
\end{array}\right)\left(\begin{array}{c}
p_{0} \\
q_{2} \\
q_{1} \\
\tau_{0}
\end{array}\right)-\left(\begin{array}{c}
d_{3}-a_{1} \\
d_{2}-a_{0} \\
d_{1} \\
d_{0}
\end{array}\right)
$$

Where

$$
d_{0}=\alpha^{2} n_{0}, d_{1}=2 \alpha n_{0}+\alpha^{2} n_{1}, d_{2}=2 \alpha n_{1}+n_{0}+\alpha^{2}, d_{3}=n_{1}+2 \alpha
$$

\section{RESULTS AND CONCLUSION}

GMC controller is implemented in real time system and the results are shown in Fig.10 with various setpoint and the adaptive controller is simulated using MATLAB-2010 - SIMULINK and its closed loop response is shown in Fig.11and Fig.12 with various setpoint. In both cases cold water flow rate is used as the manipulated variable. Satisfactory results were obtained in simulation and real time experimentation and the controller effort taken by the nonlinear controller is comparatively less compared to the conventional controllers designed for this particular experimentation setup [4] 


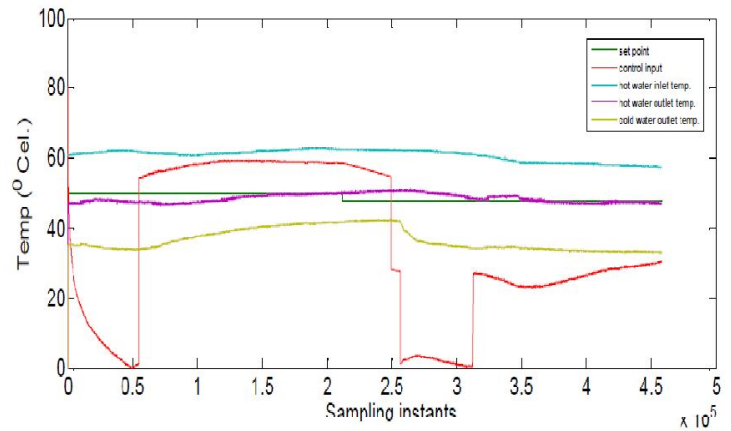

Fig 10. Closed Loop Response Of The GMC Controller With The Real Time Experimental Setup For The Setpoints $50^{\circ} \mathrm{C}$ And $48 \mathrm{C}$.

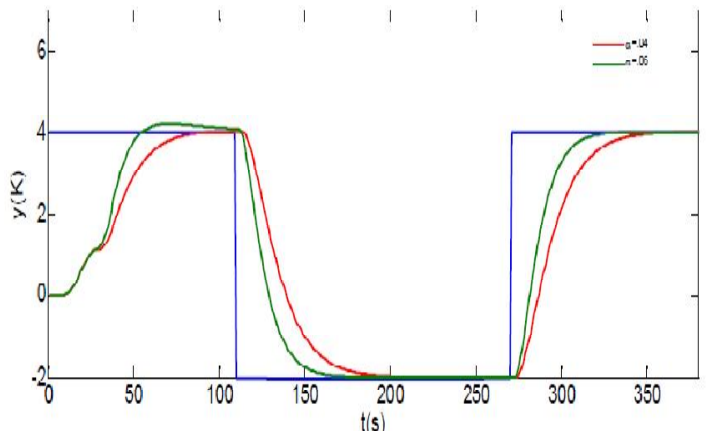

Fig 11. Controlled Output Responseof The Adaptive Controller With The Various "A" Values.

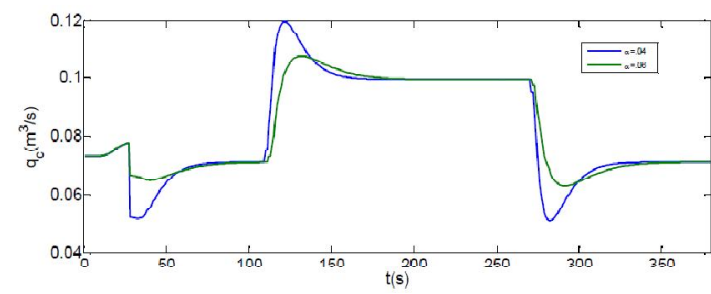

Fig 12.Cold Water Flow Rate For Various "A” Values.

\section{REFERENCES}

[1] Dostál, P. J. Vojtěšek, and V. Bobál. 2011a. "Simulation of the 2DOF nonlinear adaptive control of a chemical reactor". In: Proceedings of 25th European Conference on Modelling and Simulation, Krakow, Poland, 494-499.

[2] Dostál, P. J. Vojtěšek, and V. Bobál. 2014a. "Non linear control of shell and tube heat exchanger". In: Proceedings of 28th European Conference on Modelling and Simulation,

[3] Bobál, V., J. Böhm, J. Fessl, and J. Macháček. 2005. Digital self-tuning controllers, Springer Verlag, Berlin, 2005.

[4] Satheeshbabu.R, Dr.I.Thirunavukkarasu et al., "Temperature control of a shell and tube heat exchanger using PID algorithms", International Journal of Advancements in Electronics and Electrical Engineering - IJAEE, Vol.3, Issue.3, Sep.2014.

[5] N. K. Sinha. Identification of continuous-time systems from samples of input-output data using the $\delta$-operator. Control Theory and Advanced Technology, vol. 9, pp. 113-125, 1993 ,

[6] R. Russell Rhinehartet al"Comparison of model-based and conventional controllers on a pilot-scale heat exchanger"ISA Transactions 52 (2013) 391-405. 